\title{
A INFLUÊNCIA DO UNICEF E DA UNESCO NA EDUCAÇÃO INFANTIL BRASILEIRA CONTEMPORÂNEA
}

\author{
Maria Angélica Olivo Francisco Lucas \\ UEM \\ mangelicaofl@ibest.com.br
}

\section{RESUMO:}

Neste artigo discutimos a respeito das funções conferidas à educação infantil brasileira entre o final da década de 1970 e o final da de 1980. Para tanto, recorremos ao conteúdo sistematizado por duas áreas de conhecimento: a história da educação infantil brasileira e as políticas públicas. Na primeira parte do texto apresentamos as políticas econômicas e sociais do UNICEF e da UNESCO para a educação dos países em desenvolvimento. Na segunda parte analisamos a função compensatória atribuída à educação infantil brasileira por meio do Programa Educação Pré-Escolar: Uma Nova Perspectiva (1975) e no Projeto Casulo (1977). As críticas desferidas a esses programas foram absorvidas pelos órgãos oficiais ao lançarem o Programa Nacional de Educação Pré-Escolar (1981) conferindo à educação infantil o papel de promover o desenvolvimento harmônico e global das crianças. É esta nova função que analisamos na terceira parte deste texto. Por fim, apontamos os efeitos da influência do UNICEF e da UNESCO na definição da função de nossa educação infantil, nas décadas de 1970 e 1980, revelando que as heranças deixadas alicerçaram os passos que viriam a ser dados em direção à definição da função de cuidar e educar atribuída, na atualidade, à educação das crianças pequenas.

Palavras-chave: função da educação infantil, políticas públicas, história da educação infantil

\section{THE INFLUENCE OF UNICEF AND UNESCO ON CONTEMPORARY BRAZILIAN EARLY CHILDHOOD EDUCATION}

\begin{abstract}
:
This paper brings us a discussion on the functions conferred on the education of children in Brazil between the late 1970 and late 1980. Therefore, we resort to the systematic content in two areas of knowledge: the history of Brazilian early childhood education and public policy. In the first part we come up with economic and social policies of UNICEF and UNESCO for education in developing countries. In the second part we analyze the compensatory function attributed to the education of children in Brazil through the PreSchool Education Program: A New Perspective (1975) and Silkworm Project (1977). The criticisms paid to these programs were absorbed by official agencies by the time of launching the National Program Pre-School Education (1981) and they give the child rearing role the right to promote the harmonious and comprehensive development of children. It is this new function that we analyze in the third part of this text. Finally, we point out the effects of the influence of UNICEF and UNESCO in defining the role of our children's education, in the 1970s and 1980s. They also reveal that the legacies left underpinned the steps that would be taken towards the definition of the role of caring and educating which are attributed, up today, to the education of young children.
\end{abstract}

Keywords: role of early childhood education, public policy, history of early childhood education. 


\section{Introdução}

A educação infantil brasileira tem uma história de mais de 150 anos. Porém, os últimos 30 anos constituem-se em uma etapa importantíssima, tanto para a história deste nível de escolaridade, quanto para a da nossa educação em geral. Trata-se de um período pleno de avanços no processo de democratização da educação brasileira que ampliaram o direito não apenas ao acesso, mas também a uma educação, hoje, em busca de qualidade embora nem toda a demanda tenha sido atendida -, oferecida de forma pública por diferentes instâncias governamentais. Em se tratando da história da educação das crianças pequenas, costuma-se referir-se às últimas três décadas como história da educação infantil brasileira contemporânea.

Esse espaço de tempo foi dividido por Rosemberg (2003) em três grandes períodos ${ }^{1}$. São eles:

- $1^{\circ}$ período: “[...] entre o final dos anos 1970 e final dos anos 1980 , corresponde à implantação de um modelo de educação infantil de massa" (ROSEMBERG, 2003, p. 33);

- $2^{\circ}$ período: “[...] se iniciou com a abertura política após a ditadura militar, principalmente por meio de ações desenvolvidas por movimentos sociais que se mobilizaram em prol da Constituinte" (ROSEMBERG, 2003, p. 34);

- $3^{\circ}$ período: "[...] se instala com a aprovação e implantação da LDB, em 1996" (ROSEMBERG, 2003, p. 35).

Nesse artigo, objetivamos discutir a respeito da função conferida a educação das crianças pequenas no decorrer do primeiro momento da periodização exposta acima, que se estende do fim da década de 1970 ao fim da década de 1980, correspondendo à implantação de um modelo de educação infantil marcado pela influência preponderante do Fundo das Nações Unidas para a Infância (UNICEF) e da Organização das Nações Unidas pela Educação, Ciência e Cultura (UNESCO) ${ }^{2}$. Para tanto, recorremos ao conteúdo sistematizado por duas áreas de conhecimento: a história da educação infantil brasileira e as políticas públicas voltadas para esse nível de escolaridade.

Levamos em consideração dois princípios que devem balizar os estudos sobre a história da educação infantil e políticas públicas voltadas para esse nível de ensino, destacados por Oliveira (2002). O primeiro deles diz respeito às mudanças de concepções, crenças e valores que não ocorrem do dia para a noite. Assim, as concepções de infância, de desenvolvimento, de educação, do papel do Estado e da sociedade para com a educação das crianças pequenas que nortearam a proposição de políticas públicas e a elaboração de legislação educacional passaram por um processo de mudanças. No segundo princípio, Oliveira (2002) salienta que a definição de políticas públicas educacionais acontece em um contexto social que envolve a sociedade civil e os organismos governamentais. Por isso, a função conferida à educação das crianças de 0 a 6 anos depende da conjuntura política e econômica e da correlação de forças existentes na sociedade.

Para tanto, o presente artigo está organizado em três partes. Na primeira discutimos a forma como UNICEF e UNESCO influenciaram a educação infantil brasileira contemporânea. Na segunda e terceira partes, respectivamente, refletimos a respeito das funções voltadas para a compensação de carências das crianças e para o desenvolvimento harmônico e global das crianças conferidas às nossas creches e pré-escolas por meio das agências multilaterias anteriormente mencionadas. 


\section{A influência do UNICEF e da UNESCO}

$\mathrm{Na}$ história da nossa educação infantil, costuma-se discutir as funções a ela atribuídas tratando creches, escolas maternais, jardins de infância e pré-escolas separadamente. Kishimoto (1986), por exemplo, aponta uma dupla trajetória das instituições voltadas para o cuidado e a educação de crianças de 0 a 6 anos: a trajetória de tendência assistencialista é a das creches e escolas maternais que nasceram atreladas às necessidades do trabalho feminino industrial e que atendiam crianças oriundas de famílias pobres, em situação de abandono e desnutrição; a trajetória de tendência educacional é a dos jardins de infância e pré-escolas que atendiam, inicialmente, crianças de 4 a 6 anos de idade, oriundas de famílias com boas condições financeiras e visavam socializá-las e prepará-las para o ingresso na escola.

No entanto, segundo Kuhlmann Júnior (1998; 2000a), o fato de algumas instituições estarem atreladas a órgãos assistenciais e outras vinculadas à educação não significa que umas tenham funções educacionais e outras não. Para o autor, todas as instituições de educação infantil tiveram um projeto educacional, podendo ser este voltado para o atendimento das camadas pobres ou para as mais abastadas da população.

Vale destacar que os modelos de instituições de educação infantil que conhecemos atualmente se originaram na Europa no final do século XIX e se difundiram pelo mundo. Segundo Rosemberg (2002), até o final dos anos 1960, tanto os países desenvolvidos como os em desenvolvimento seguiam, basicamente, dois modelos institucionais: as creches, que atendiam crianças oriundas de famílias pobres, e os jardins-de-infância, destinados a crianças de lares mais abastados.

No Brasil, as histórias dessas instituições caminharam de forma paralela durante mais de um século, mas, paradoxalmente, nas últimas décadas, se aproximaram uma da outra, a ponto de se tornarem uma, hoje denominada educação infantil. organismos:

Rosemberg (2002, p. 7) atribui o início dessa cisão à influência da ONU e seus

Essa trajetória relativamente comum se cinde ao final da década de 1960, quando a educação infantil passou a integrar, também, a agenda das políticas de desenvolvimento econômico e social elaborada pelos organismos vinculados à ONU (Organização das Nações Unidas) para os países subdesenvolvidos, especialmente aquelas pensadas para as excolônias européias da Ásia e da África (ROSEMBERG, 2002, p. 7).

A autora acima citada, ao estudar com profundidade as políticas propostas pelos principais organismos vinculados à ONU - UNICEF e UNESCO -, detectou os principais princípios do modelo de educação infantil por elas sugerido para os países em desenvolvimento e assim os organizou:

- a expansão da educação infantil constitui uma via para combater a pobreza nos países subdesenvolvidos e melhorar o desempenho no ensino fundamental, portanto, sua cobertura deve crescer;

- os países pobres não dispõem de recursos públicos para expandir, simultaneamente, o ensino fundamental (prioridade número um) e a educação infantil;

- a forma de expandir a educação infantil nos países subdesenvolvidos é por meio de modelos que minimizem investimentos públicos, dada a prioridade de universalização do ensino fundamental; 
- para reduzir os investimentos públicos, os programas devem se apoiar nos recursos da comunidade, criando programas denominados "não formais", "alternativos", "não-institucionais", isto é, espaços, materiais, equipamentos e recursos humanos disponíveis na "comunidade", mesmo quando não tenham sido concebidos ou preparados para essa faixa etária e para seus objetivos (ROSEMBERG, 2002, p. 7-8).

Esse modelo de educação infantil foi gradualmente elaborado e divulgado por meio de missões em países considerados em desenvolvimento, realização de seminários internacionais e regionais, assessoria de especialistas e publicações diversas. Essas publicações divulgavam sugestões de modalidades de educação infantil e estratégias para reduzir os custos como sendo as melhores soluções para o desenvolvimento das crianças.

No Brasil, a partir de meados dos anos 1970, durante o governo militar, o modelo de educação infantil não-formal com pequeno investimento público voltado para as crianças pobres, proposto pelo UNICEF e pela UNESCO, encontrou terreno fértil para sua proliferação. Era necessário combater a pobreza, pois esta era uma ameaça à segurança nacional, por meio de políticas de assistência, entre elas os programas de educação infantil.

Nesse período, foram poucos os recursos advindos desses organismos aplicados diretamente ao financiamento de projetos voltados para o trabalho com crianças. A maior parte dos recursos financeiros era aplicada em vindas de especialistas, na orientação de técnicos e profissionais e para a realização de pesquisas. Para Rosemberg $(2002$, p. 6), o que ocorreu foi, sobretudo, "[...] circulação de idéias da UNESCO e do UNICEF entre formadores de opinião e tomadores de decisão no plano das políticas educacionais brasileiras e pouco financiamento direto de projetos para implantar programas de educação infantil".

Com o objetivo de despender poucas verbas do Estado, as políticas econômicas e sociais de tais agências multilaterais para a educação dos países em desenvolvimento tinham a finalidade de compensar as carências das crianças oriundas de famílias pobres, utilizando recursos da comunidade, ou seja, eram de cunho compensatório. Tais idéias difundiram-se ao ponto de, a partir das críticas que a elas foram desferidas, a educação das crianças pequenas passar a ser concebida como com "objetivos em si mesma", esvaziandose de função. São estas funções conferidas à educação infantil brasileira contemporânea que, a seguir, exporemos detalhadamente.

\section{Compensação de carências das crianças}

O golpe militar de 1964, no Brasil, estabeleceu um longo período de ditadura que cerceou a liberdade de expressão e organização da sociedade civil. A nossa imprensa foi censurada, sindicatos, partidos políticos e associações de classe foram fechados e proibidos, opositores ao regime foram presos, torturados, exilados, desaparecidos ou assassinados. Michiles (1989 ${ }^{3}$, apud Munerato, 2001, p. 29) caracteriza essa época como um "[...] período de inoportunidade conjuntural para questões de mobilização e reivindicações da sociedade, em virtude do controle imposto pelas classes dominantes, que não toleravam nenhuma alteração das regras do jogo político vigente".

Apesar disso, a partir de meados da década de 1970, foram emergindo, nas grandes cidades, manifestações de grupos organizados da sociedade civil que tinham como pólo aglutinador o local de moradia e as relações de vizinhança, parentesco ou amizade. Um exemplo desses grupos é o de mulheres, lembra-nos Rosemberg (1984), que participavam intensamente das manifestações e dos movimentos por meio de organizações como clubes 
de mães e associações de bairros. Também surgem em nosso país, nessa mesma época, organizações feministas, principalmente a partir de 1975, com a decretação pela ONU do Ano Internacional da Mulher. Mesmo as reivindicações sendo divergentes em relação à discriminação de gênero, tanto o movimento de mulheres, como o movimento feminista pleiteavam creches e pré-escolas.

Nesse mesmo período, já como resposta às reivindicações iniciais, a educação da criança pequena começa a receber atenção do poder público. Isso pode ser comprovado com a publicação do Parecer n. 2018/74 do Conselho Federal de Educação (CFE); a criação, em 1974, do Serviço de Educação Pré-Escolar (SEPRE) subordinado ao MEC, transformado no ano seguinte em Coordenadoria de Educação Pré-Escolar (COEPRE); a publicação do Programa Educação Pré-Escolar: Uma Nova Perspectiva, também em 1975; a realização do $1^{\circ}$ Encontro de Coordenadores de Educação Pré-Escolar, em Brasília, nesse mesmo ano; e a implantação do Projeto Casulo, em 1977, pela Legião Brasileira de Assistência (LBA).

Para Rosemberg (1992), por meio dessas ações, programas e projetos, dava-se início ao processo de expansão das pré-escolas, indicando a opção dos órgãos governamentais por programas de cunho compensatório para as massas. A preocupação com a educação das crianças pequenas, principalmente as pobres e marginalizadas, por parte do poder público, segundo Kramer e Souza (1987, p. 18),

[...] pode ser interpretada como uma tentativa de encontrar, naquele momento, uma solução para um impasse político. Se, por um lado, o discurso oficial apontava a pré-escola como uma necessidade inadiável, por outro, o planejamento orçamentário da União continuava sem uma política de dotação de verbas que pudesse cobrir as reais necessidades da educação no país.

Se anteriormente o pré-primário, como era chamado, era freqüentado por crianças pertencentes às famílias abastadas, o poder público viu-se naquele momento obrigado a voltar seus esforços para o atendimento das crianças oriundas de famílias pobres. Tratavase de criar, utilizando uma expressão de Rosemberg (1992, p. 25), uma "pré-escola de massa", calcada em programas de educação compensatória, que tinham como pressuposto a teoria da privação cultural ${ }^{4}$ (FERRARI; GASPARY, 1980).

De acordo com esta visão, a pré-escola, em substituição à educação pré-primária, teria a função de prever e compensar as carências culturais, nutricionais e afetivas das crianças advindas de famílias pobres. Dessa forma, as oportunidades educacionais seriam equalizadas. Nessa lógica, a pré-escola era considerada pré-requisito para um bom desempenho da criança na fase da escolarização, como uma primeira etapa desse processo, assumindo-se como educação formal e sistematizada. Assim, se as crianças carentes apresentavam dificuldade para aprender, fazia-se necessário antecipar o início da aprendizagem escolar. É exatamente nessa direção que caminharam as recomendações do Parecer n. 2078/74 do CFE:

[...] voltar-se o atendimento para as crianças oriundas das famílias de baixa renda, visando com isso, a equalizar as oportunidades educacionais, não apenas no sentido do acesso, mas também, no intuito de garantir a permanência dessas crianças na escola, fornecendo-lhes uma formação mais consistente, que compensasse a marginalização e carência cultural a que estavam submetidas em seu meio (ABRANTES, 1984, p. 17). 
Estas recomendações inspiraram as diretrizes do programa Educação Pré-Escolar: Uma Nova Perspectiva, elaborado pelo SEPRE/MEC, em 1975. Tal programa, ao absorver as recomendações do UNICEF e da UNESCO, considerava que:

[...] educação, nutrição e saúde deveriam ser atendidas de forma integrada; utilizando de espaços físicos disponíveis na comunidade; a família e a comunidade fariam parte integrante das atividades de educação pré-escolar, objetivando despertar a consciência sobre a importância da idade pré-escolar e o barateamento dos programas; os meios de comunicação de massa deveriam ser utilizados como forma de atingir populações distanciadas do espaço escolar (ROSEMBERG, 1992, p. 25).

Para difundir esse programa, o MEC desenvolveu várias ações previstas no II Plano Setorial de Educação e Cultura - II PSEC (1975-1979), que destinava 2,5\% do total de recursos previstos exclusivamente para essas ações.

O II PSEC concebeu a educação pré-escolar na perspectiva da compensação das carências das populações pobres visando sua inserção na escolaridade formal. $\mathrm{O}$ objetivo quanto à educação pré-escolar consistiria em "desenvolver um processo progressivo para atendimento à população das zonas urbanas marginais, na faixa etária de 4 a 6 anos, de modo a assegurar maior adaptação sócio-pedagógica do educando ao ensino regular" (BRASIL, 1977, p. $35^{5}$ apud ROSEMBERG, 1992, p. 26).

Esses ideais inspiraram o primeiro programa brasileiro de educação infantil de massa, não mais desenvolvido pelo MEC, mas pela LBA - o Projeto Casulo. Segundo Rosemberg (1997, p. 153), além das recomendações das agências multilaterais, a ideologia da Doutrina Brasileira de Segurança Nacional (DSN) também embasou teoricamente e orientou a criação desse projeto. O Projeto Casulo fazia parte das estratégias de combate à pobreza, pois esta era vista como uma ameaça à integração nacional. De acordo com essa ótica, "investir na criança [pobre] significaria investir na segurança nacional".

O Projeto Casulo foi lançado em 1977 e rapidamente se expandiu, ultrapassando a meta prefixada de atender a 70 mil crianças no primeiro ano de implantação, tornando-se, a partir de 1981, o principal programa da LBA. Essa expansão foi realizada com a utilização de recursos da comunidade: espaços ociosos e pessoas sem formação específica que atuavam em condições de trabalho precárias (BARRETO, 2003). Portanto, o Projeto Casulo bem exemplifica as propostas de atendimento em grande escala e a baixo custo voltadas para as crianças das camadas populares, seguindo os modelos preconizados pela UNESCO e pelo UNICEF (CORRÊA, 2002).

Tal projeto oferecia vagas predominantemente em meio período (turno de 4 horas), sobretudo para crianças a partir dos 4 anos de idade. A LBA atuava de forma indireta, repassando recursos a instituições privadas e prefeituras. Para multiplicar o número de instituições destinadas às crianças pequenas em todo o país, o valor do per capita dos recursos repassados foi reduzido ${ }^{6}$ (KUHLMANN JÚNIOR, 2000b). Com isso, os recursos continuavam os mesmos, mas para serem divididos por um número maior de crianças. Campos, Rosemberg e Ferreira (2001, p. 32) sintetizam algumas características desse programa, dizendo: 
Trata-se de um programa nacional (provavelmente o único), seja por sua abrangência territorial, seja pelo fato de definir metas nacionais de atendimento, apesar da diversidade das creches a ele vinculadas; sua opção tem sido por uma atuação através de convênios, repassando verbas seja às prefeituras ou a instituições privadas [...]; atende prioritariamente a população de baixa renda; a jornada diária pode ser de 4 ou 8 horas (corresponde a per capitas diferentes); as creches são instaladas em equipamentos simples, procurando aproveitar espaços "ociosos" da comunidade, e são orientadas por uma concepção preventiva e compensatória de atendimento infantil.

Contudo, as reivindicações sociais continuavam. O movimento de mulheres, o movimento feminista e outros simpatizantes da causa que envolvia a educação das crianças pequenas marcavam presença nos congressos, nas associações de bairro e nos sindicatos, colocando em discussão a responsabilidade da sociedade em relação à educação das novas gerações. Para tanto, defendiam que

[...] a responsabilidade pela educação da criança pequena não é só da mãe, nem da família, mas é também de todos; ou seja, o Estado, enquanto gerente dos recursos arrecadados de toda a sociedade, tem o dever de contribuir para a educação integral das crianças, desde seu nascimento (CAMPOS, 1988, p. 23).

Segundo Kramer (1988), foi somente a partir do final da década de 1970 que a luta por creches e pré-escolas ganhou força e se multiplicou. Muitas manifestações públicas de impacto em torno da reivindicação por creches aconteceram nesse momento. São destacadas por Rosemberg (1984) as seguintes: a manifestação de mulheres de um bairro da periferia de São Paulo diante da Prefeitura daquela cidade, e a marcha realizada por funcionários, alunos e professores da Universidade de São Paulo por reforçar uma frente de luta que vinculava a creche ao local de trabalho e não ao local de moradia.

O que de início eram manifestações isoladas, transformou-se em movimento unitário - o Movimento de Luta por Creches - criado oficialmente em $1979^{7}$. Reivindicar creche tornou-se, naquele momento, uma palavra de ordem. Creche tornou-se um símbolo de luta dos movimentos sociais, dos grupos políticos que se opunham à ditadura militar, dos movimentos estudantis que reabriam centros acadêmicos e realizavam passeatas a favor da democracia, do Movimento de Luta Contra a Carestia de Vida, das organizações populares dos bairros da periferia, dos operários de diversas classes trabalhadoras que realizavam greves que se espalhavam por todo o território nacional. Enfim, a reivindicação por creches e pré-escolas foi incorporada pelo quadro das bandeiras pela redemocratização do país (KUHLMANN JÚNIOR, 1998; 2000b).

No início da década de 1980, em resposta às reivindicações populares e à crise de legitimidade do governo militar, na área de política educacional, o III PSEC (1980-1985) incluiu a educação pré-escolar como parte essencial da política social e educacional. A exemplo do II PSEC, muitas críticas foram feitas à concepção de educação pré-escolar do III PSEC no sentido de que ela pudesse resolver alguns dos problemas que as crianças das camadas mais pobres enfrentavam no seu processo de aprendizagem e desenvolvimento por sofrerem muitas privações no meio em que viviam. Assim, estas crianças, recebendo uma educação pré-escolar, teriam possibilidade de recuperar seus déficits cognitivo, afetivo e social, podendo acompanhar as tarefas escolares (ABRANTES, 1984; DIDONET, 1992). Abrantes (1984) ironicamente critica a concepção de pré-escola do III PSEC: 
A pré-escola seria a medida de apoio, ao nível de sistema escolar formal, ao projeto de combate à pobreza e à "marginalidade". Através dela, as distorções escolares seriam corrigidas. Os efeitos negativos sobre os indivíduos, em seus primeiros anos de vida, suscitados pela pobreza cultural, pela desnutrição, pela falta de estímulo das comunidades "carentes", seriam neutralizados. Com isso, inapelavelmente, os díspares desempenhos escolares tenderiam a se equilibrar. A ascensão social seria uma realidade. A "marginalidade social", um fato ultrapassado (ABRANTES, 1984, p. 16).

No entanto, Didonet (1992, p. 20), com uma visão mais otimista, afirma que

Independentemente das críticas que surgiram à concepção da educação pré-escolar presente no III PSEC, carece destacar-se que o fato de a préescolar ter figurado explicitamente num plano nacional de educação foi uma conquista importante, respaldada e legitimada por quantos participaram de sua elaboração: órgãos técnicos do MEC, secretarias estaduais de educação, conselhos de educação, etc. Até então, a educação pré-escolar lutava por espaço técnico no MEC e nas secretarias de educação e por recursos financeiros, que não conseguiam ser expressivos para permitir ações de envergadura. O PSEC lhe deu status e condições de afirmação política e de argumentação junto ao setor de planejamento e de orçamento.

Esses programas pré-escolares com função compensatória começaram a ser muito criticados no Brasil, principalmente a partir do final da década de 1970. Foi estabelecido um consenso de que programas com esse cunho efetivamente não beneficiam as crianças mais pobres da população às quais se destinavam, mas que, pelo contrário, as discriminavam e as marginalizavam ainda mais precocemente.

Concomitantemente às críticas, verificou-se que, na realidade, foi quase nulo o impacto desses programas no sistema educacional. As matrículas quase não aumentaram e poucas mudanças que indicassem a implantação de um modelo de pré-escola de massa efetivamente ocorreram. Nesse sentido, Kramer (1988) considera importante ressaltar que, em termos concretos, a COEPRE não implementou efetivamente nenhum programa de educação pré-escolar de cunho compensatório. O que ocorreu foi a influência do discurso pautado na teoria da privação cultural e nos programas de educação compensatória no ideário dos professores, não apenas dos que atuavam na a pré-escola, mas também no então $1^{\circ}$ grau.

\section{Desenvolvimento harmônico e global das crianças}

O discurso oficial incorporou as críticas dirigidas aos programas de educação infantil de cunho compensatório, promovendo alterações nas propostas do MEC por meio do Programa Nacional de Educação Pré-Escolar, lançado em 1981. Seu documento de origem estabelece as diretrizes, prioridades, metas, estratégias e um plano de ação para a política voltada para as crianças em idade pré-escolar. A análise dos objetivos e das diretrizes desse programa revela tentativa de responder às críticas e inconsistência em relação aos pressupostos que embasavam a proposta anterior e que retornavam com uma nova roupagem, ou nus, como disseram Abramovay e Kramer (1984), parafraseando Hans Christian Andersen no conto "A roupa nova do imperador". 
Nessa análise, as autoras verificaram que, de acordo com o Programa Nacional de Educação Pré-Escolar, a função da pré-escola não seria mais preparar para a escolarização posterior. Pelo contrário, seu objetivo deveria voltar-se para o desenvolvimento global e harmônico da criança, respeitando suas características físicas e psicológicas, de acordo com a sua idade, cultura e comunidade. "Ela tem, portanto, objetivos em si mesma, próprios da faixa etária e adequados às necessidades do meio físico, social, econômico e cultural." (BRASIL, 1982, p. $11^{8}$ apud ABRAMOVAY; KRAMER, 1984, p. 32).

Segundo tal programa, ao respeitar as características e necessidades próprias da criança, a pré-escola estaria ajudando-a a superar os problemas oriundos da falta de recursos de sua família, gerando, por sua vez, efeitos positivos para a aprendizagem e contribuindo para que a criança, posteriormente, apresentasse melhor desempenho escolar. Essa seria a contribuição da pré-escola para diminuir o problema de evasão e de repetência das primeiras séries do então $1^{\circ}$ grau.

Ao analisar minuciosamente o documento-origem do Programa Nacional de Educação Pré-Escolar, Abramovay e Kramer (1984, p. 33) afirmam:

Deixa-se de proclamar a função compensatória da pré-escola, mas a defesa de sua importância continua tendo enfoque político visível. A préescola não cura mais os males educacionais, mas sim os sociais e estes, por tabela, auxiliarão a resolver os educacionais ...

Há um esvaziamento da função da pré-escola, pois sob o disfarce do que tem objetivo em si mesma, caberia tudo. Fica de lado a discussão sobre o tipo de pré-escola que traria contribuições reais às crianças das classes populares, pois a pré-escola é considerada importante em e por si mesma $[\ldots]$.

Uma pré-escola forjada nestes moldes pode ser informal, não-convencional, assistemática e nem necessita de qualidade, criticam as autoras. E questionam:

\begin{abstract}
Até que ponto a pré-escola, "com objetivos em si mesma", não serve para justificar uma proposta que se isenta de estabelecer critérios mínimos de qualidade, tais como: número de crianças por unidade, de forma a garantir um trabalho sistemático de acompanhamento das crianças; estratégias de treinamento - e suporte técnico - que assegurem uma prática pedagógica consistente; um sistema de supervisão contínua que permita um repensar das práticas desenvolvidas; formas de avaliação que envolvam as pessoas dos diversos níveis do programa - capazes de oferecer subsídios para a sua reestruturação; efetiva vinculação trabalhista que substitua o voluntariado das mães? (ABRAMOVAY; KRAMER,1984, p. 34).
\end{abstract}

A despeito das críticas, o Programa Nacional de Educação Pré-escolar cresceu e se expandiu por todo o território nacional, por meio de convênios com as secretarias de educação estaduais e municipais, a baixo custo, em grandes espaços ociosos (com capacidade para 100 crianças, em média) e utilizando mão-de-obra voluntária não especializada.

Ainda em 1981, o Movimento Brasileiro de Alfabetização (MOBRAL), instituição voltada para a alfabetização e educação continuada de adolescentes e adultos, passou a integrar o Programa Nacional de Educação Pré-Escolar. O Programa de Educação PréEscolar do MOBRAL, que fazia parte do Programa Nacional coordenado pelo MEC, interiorizou-se, expandindo sua ação, a ponto de, já em 1982, ser responsável por $50 \%$ do 
atendimento pré-escolar da rede pública. Para poder participar do programa, as secretarias estaduais e municipais tiveram que se aparelhar, criando, inclusive, coordenações específicas para a área pré-escolar. Em 1983, as atividades do Programa de Educação Préescolar foram mantidas, mas sem os recursos humanos e financeiros necessários, deixando de ser o programa prioritário do MOBRAL. Quando o MOBRAL foi extinto, em 1985, o Programa foi transferido para a Secretaria de Ensino de $1^{\circ}$ e $2^{\circ}$ grau do MEC. Dois anos mais tarde, quando da extinção do COEPRE, o Programa foi inserido na Secretaria de Educação Básica (SEB), que manteve as metas, estabelecendo convênios com as prefeituras para continuar o atendimento (ABRANTES, 1984; KRAMER; SOUZA, 1987; DIDONET, 1992).

Ao fazer um balanço da educação infantil nos anos 1980, Didonet (1992) considerou a criação do Programa Nacional de Educação Pré-Escolar um dos importantes momentos para a pré-escola na área de política educacional e programas da década. Além desse programa, foram considerados relevantes para a expansão da educação pré-escolar na década de 1980:

a. o Programa de Capacitação de Professores de Educação Pré-Escolar (PROEPRE), desenvolvido em várias secretarias estaduais de educação. As pessoas que participavam dos cursos promovidos pelo PROEPRE tornavam-se multiplicadores e tinham a responsabilidade de repassar aos demais professores o conteúdo do curso;

b. o programa Zero a Seis, o Primeiro Mundo, produzido pela Fundação Roberto Marinho, em convênio com o MEC, que abordava assuntos relacionados aos cuidados e à educação da criança, desde a concepção até os seis anos de idade. Este programa era dirigido aos pais e veiculado em rede nacional;

c. o programa Primeiro a Criança, em 1986, que ficou sob a responsabilidade da LBA, restringindo-se à assistência e alimentação.

Enfim, a educação da criança de 0 a 6 anos começou a ser reconhecida, tanto pela sociedade, como pelo poder público, que, apesar da forma incipiente, ampliou o atendimento, em especial o destinado às crianças de 4 a 6 anos, mesmo antes deste nível de escolaridade ser assumido, legalmente, como dever do Estado. Alguns passos haviam sido dados em direção à democratização desse nível de escolaridade. Prova disso, é que pode ser observado, já no final da década de 1970 e durante a década de 1980, uma sensível expansão da quantidade de creches e pré-escolas em nosso país (KRAMER, 1987; ROSEMBERG, 1984).

Vários autores apresentam em seus textos dados estatísticos que comprovam a ampliação das creches e pré-escolas em nosso país. Segundo Abrantes (1984), as nossas primeiras estatísticas sobre a educação pré-escolar datam do início da década de 1970, primeiramente no Anuário Estatístico do Brasil, em 1974 e na Sinopse Estatística do $1^{\circ}$ grau 1969-1975. Kramer e Souza (1987) advertem para o fato de as estatísticas nesse momento serem muito ambíguas, por vezes incompletas e contraditórias. É importante esclarecer que muitas dessas estatísticas não incluíam as crianças com menos de 4 anos que eram atendidas em creches. Sabe-se apenas que em torno de $12 \%$ do total de matrículas eram de crianças com idade inferior a 4 anos.

Os dados mais recentes são mais precisos quanto à idade da criança e à instituição frequientada. Em 1972, de acordo com dados oficiais do MEC, havia 460 mil matrículas na pré-escola, chegando em 1984 a quase 2 milhões e 500 mil e, em 1997, a 4 milhões e 292 mil. Adicionadas a este último número, as crianças que freqüentavam creches e classes de alfabetização totalizam pouco mais de 6 milhões de matrículas (KUHLMANN, 2000b). Comparando-as com a população total de crianças, em 1980, 1.335 .317 crianças tinham 
acesso à pré-escola, equivalendo a 5,8\% da população de 0 a 6 anos, que era de 22.536 .386 e a $13 \%$ da população de 4 a 6 anos, que era de 8.182.812 (MEC/SAG/CPS/CIP, 1990 apud D1DONET, 1992, p. 21.

Ao analisar a distribuição do aumento de matrículas entre as esferas municipal, estadual e federal, Didonet (1992, p. 25) constatou que:

[..] entre 1979 e 1989, o número de crianças matriculadas triplicou: das 1.198.104 daquele ano, passou-se para 3.530 .000 em 1989. O aumento maior ocorreu na esfera municipal (de 356.006 para 1.400 .000 crianças), em seguida, na estadual (de 290.175 para 900.000) e, em terceiro lugar, na área da iniciativa privada (de 545.506 para 1.200 .000 ). Na esfera federal, o aumento percentual é grande, mas em números absolutos significa pouco (de 6.417 para 30.000 matrículas).

Muitas são as razões levantadas por diferentes pesquisadores para tal expansão. Para Redin (1988, p. 29), seu início se deve a mudanças no modelo econômico brasileiro: "[...] do modelo de substituição das importações, num país industrial capitalista, o País ingressa no modelo de internacionalização do mercado interno". Os sucessivos governos voltaram-se para a questão da educação escolar das chamadas classes populares, pois era preciso qualificar a força de trabalho, visando ao aumento da produção. No entanto, diante dos alarmantes índices de evasão e repetência, que evidenciaram a incapacidade da escola em qualificar o indivíduo para o mercado de trabalho, atentou-se para a necessidade de educação pré-escolar. Assim, Redin (1988) considera o fracasso da escola primária uma das principais causas para a expansão das creches e, principalmente, das pré-escolas nas décadas de 1970 e 1980.

Para Didonet (1992), a crise econômica que reinou por quase toda a década de 1980 é também uma das causas do aumento das creches e pré-escolas no Brasil nesse período. Tal crise, marcada por índices elevados de inflação, ocasionou a queda do poder aquisitivo da maioria da população e o desemprego em larga escala, levando muitas famílias a procurarem creches e pré-escolas para que seus filhos pudessem receber alimentação, cuidados de saúde e educação. Nesse mesmo contexto, cresceu a participação da mulher no mercado de trabalho, por necessidade econômica ou por consequiência das lutas por igualdade de direitos sociais, políticos e econômicos. Como pai e mãe precisavam trabalhar, foi necessário buscar alternativas para o cuidado e a educação das crianças menores de 7 anos, tais como creches e pré-escolas.

Concomitante à entrada da mulher no mercado de trabalho, que exigiu seu afastamento das tarefas domésticas e do cuidado dos filhos, há que se destacar o reconhecimento pela sociedade da importância das primeiras experiências da criança para o seu desenvolvimento, como uma das razões do aumento da demanda por escolarização de crianças com idade inferior a 7 anos e da expansão das creches e pré-escolas, afirma Barreto (1995). Colaboraram para isso as descobertas da história, da psicologia, da lingüística e da antropologia, ao mostrarem que a criança, nos primeiros anos de vida, passa por um processo rico de crescimento, sendo importante garantir-lhe condições adequadas para que tal desenvolvimento ocorra (CAMPOS, 1988; KRAMER, 1988). Como decorrência da divulgação desses novos conhecimentos científicos, os pais passaram a acreditar que a freqüência em creches e pré-escolas seria condição para melhor desempenho no ensino fundamental, exigindo creches e pré-escolas para seus filhos pequenos.

Além dos autores já citados, também Vieira (1999) relaciona outros determinantes dessa expansão: o novo perfil demográfico da população brasileira (urbanização da família 
e diminuição de seu tamanho, tanto na cidade, como no campo); o início da crise política do regime militar; a influência da UNESCO e do UNICEF nas políticas sociais dos países pobres, exigindo que estas fossem de baixo custo.

Esse primeiro período da história da educação infantil brasileira contemporânea, conforme periodização anteriormente exposta, além da expansão das matrículas, deixounos outras heranças, afirma Rosemberg (2003, p. 34). Entre elas, destacamos:

a organização de uma estrutura administrativa específica, no interior do Ministério da Educação com estatuto de Coordenadoria (Coordenação de Educação Infantil/COEDI) vinculada à Secretaria de Ensino Fundamental; a penetração dos chamados modelos "não-formais", apoiados em recursos improvisados (espaço físico, material pedagógico, mão-de-obra); a criação de creches e pré-escolas comunitárias; sua municipalização; o recurso a educadores(as) leigos(as), isto é, com formação inferior ao curso normal ou secundário; a retenção de crianças tendo 7 anos e mais em programas de educação infantil; a consolidação de três denominações/modalidades de educação infantil - creches, pré-escolas e classes de alfabetização; o envolvimento dos novos movimentos sociais no campo da educação infantil; a constituição de um embrião de expertise nacional.

Não podemos negar, por fim, que algumas dessas heranças provocaram efeitos nefastos, porém lançaram bases para a busca de um modelo de educação infantil de qualidade para todas as crianças brasileiras, ainda hoje em processo de construção.

\section{Algumas considerações finais}

Apontamos neste artigo, as funções atribuídas à nossa educação infantil durante o primeiro momento da periodização organizada por Rosemberg (2003) - final da década de 1970 ao final da de 1980 - tomando como principal referência discussões sistematizadas por duas áreas de conhecimento: políticas públicas e história da educação.

O relato detalhado da trajetória da educação infantil brasileira no período em análise, além de esclarecer os retrocessos, valorizou cada pequeno e gradual avanço, principalmente quando foram explicitadas a conjuntura econômica e política e a correlação de forças existentes na sociedade no momento em que diferentes propostas referentes às nossas creches e pré-escolas foram elaboradas e implantadas. Optamos por abordar, conjuntamente, as histórias dessas duas instituições - creches e pré-escolas - por acreditarmos que as conquistas, os impasses e problemas que ambas enfrentaram ao longo de suas distintas trajetórias colaboraram não apenas para a construção de suas respectivas histórias, mas para a da educação infantil brasileira como um todo (LUCAS, 2008).

Verificamos que o início da expansão do atendimento às crianças pequenas se deu por meio de programas de educação pré-escolar, que tinham como função prever e compensar déficits cognitivos, nutricionais e afetivos das crianças oriundas das camadas mais pobres da população, preparando-as para a próxima fase de escolarização e, concomitantemente, combatendo a pobreza e a marginalidade.

Muitas críticas foram desferidas a esses programas, as quais foram incorporadas pelos órgãos por eles responsáveis, que, por sua vez, os revestiram de uma nova roupagem, definindo-lhes outras finalidades, como promover o desenvolvimento global e harmônico da criança. Com essa função, a educação infantil, ao respeitar as características físicas e psicológicas de cada criança de acordo com sua idade, cultura e origem social, estaria 
contribuindo para superar os problemas sociais e educacionais evidenciados, naquele momento, pelos altos índices de evasão e repetência, principalmente da $1^{\mathrm{a}}$ para a $2^{\mathrm{a}}$ série do então $1^{\circ}$ grau. Tratava-se do esvaziamento da função da educação infantil, que, forjada nesses moldes, teria "objetivos em si mesma", não carecendo de trabalho sistematizado e intencional, de profissionais com formação adequada, de espaço físico previamente planejado e preparado e de materiais pedagógicos. Foi dessa forma que se deu a expansão da educação das crianças pequenas na década de 1980.

Por fim, constatamos que, a partir de meados da década de 1970, a educação das crianças pequenas foi influenciada muito mais pelo ideário divulgado pelo UNICEF e pela UNESCO, do que por investimentos oriundos dessas agências multilaterais. Apesar dessa forma de influência ter efeitos duradouros e deletérios, como demonstramos no final deste artigo por meio dos estudos realizados por Barreto (1995), Campos (1988), Kramer (1988), Vieira (1999) e Rosemberg (2003) que apontaram as causas do início da expansão da nossa educação infantil e as heranças deixadas, eles alicerçaram os passos que viriam a ser dados no segundo momento da história da educação infantil brasileira contemporânea. Iniciado pelo processo de abertura política, após a ditadura militar, e marcado pelas ações desenvolvidas por movimentos sociais que se mobilizaram em prol da Constituinte, esse novo período caracterizou-se, segundo Kramer (1987), como de intensa mobilização política, rico em discussões e propostas que envolviam a busca de uma função pedagógica para a educação das crianças pequenas, o qual viria se consolidar, nos dias atuais, por meio do reconhecimento da necessidade de, concomitantemente, cuidá-las e educá-las.

\section{Referências}

ABRAMOVAY, Miriam; KRAMER, Sonia. "O rei está nu": um debate sobre as funções da pré-escola. Cadernos CEDES, São Paulo, Cortez, n. 9, p. 27-38, 1984.

ABRANTES, Paulo Roberto. O pré e a parábola da pobreza. Cadernos CEDES, São Paulo, Cortez, n. 9, p. 8-26, 1984.

BARRETO, Ângela Maria Rabelo Ferreira. Educação infantil no Brasil: desafios colocados. Cadernos CEDES, Campinas, Papirus, n. 37, p. 7-21, 1995.

BARRETO, Ângela Maria Rabelo Ferreira. A educação infantil no contexto das políticas públicas. Revista Brasileira de Educação, Rio de Janeiro, n. 24, p. 53-65, 2003.

CAMPOS, Maria Malta. Pré-escola e sociedade: determinantes históricos. Idéias, São Paulo, FDE, n. 2, p. 22-26, 1988.

CAMPOS, Maria Malta; ROSEMBERG, Fúlvia; FERREIRA, Isabel M. Creches e préescolas no Brasil. São Paulo: Cortez, Fundação Carlos Chagas, 2001.

CORRÊA, Bianca Cristina. Educação infantil. In: OLIVEIRA, Romualdo Portela;

ADRIÃO, Theresa (orgs.). Organização do ensino no Brasil: níveis e modalidades na Constituição Federal e na LDB. São Paulo, Xamã, 2002. p. 17-28.

DIDONET, Vital. Balanço crítico da educação pré-escolar nos anos 80 e perspectivas para a década de 90. Em Aberto, Brasília, n. 50/51, p. 19-33, abr./set. 1992.

FERRARI, Alceu R., GASPARY, Lúcia Beatriz Velloso. Distribuição de oportunidades de educação pré-escolar no Brasil. Educação e Sociedade, São Paulo, Cortez, Autores Associados, n. 5, p. 62-79, jan. 1980.

KISHIMOTO, Tizuko Morchida. A pré-escola em São Paulo (1877 a 1940). São Paulo, Loyola, 1986. 
KRAMER, Sonia. A política do pré-escolar no Brasil: a arte do disfarce. Rio de Janeiro, Dois pontos, 1987.

A pré-escola como direito social. Idéias, São Paulo, FDE, n. 2, p. 13-17, 1988.

KRAMER, Sonia; SOUZA, Solange Jobim. Avanços, retrocessos e impasses da política de educação pré-escolar no Brasil. Educação e Sociedade, São Paulo, Cortez, n. 28, p. 12-31, dez. 1987.

KUHLMANN JÚNIOR, Moysés. Infância e educação infantil: uma abordagem histórica. Porto Alegre: Mediação, 1998.

. Educação infantil e currículo. In: FARIA, Ana Lúcia Goulart de; PALHARES, Marina Silveira (Orgs.). Educação infantil pós-LDB: rumos e desafios. Campinas: Autores Associados - FE/UNICAMP; São Carlos: Editora da UFSCar; Florianópolis: Editora da UFSC, 2000a. p. 51-65.

Educando a infância brasileira. In: LOPES, Eliane Marta Teixeira; FARIA FILHO, Luciano Mendes de; VEIGA, Cynthia Greive. 500 anos de educação no Brasil. Belo Horizonte: Autêntica, 2000b. p. 469-496.

LUCAS, Maria Angélica Olivo Francisco. Os processos de alfabetização e letramento na educação infantil: contribuições teóricas e concepções de professores. 2008. Tese (Doutorado em Educação) - Universidade de São Paulo, São Paulo, 2009.

MUNERATO, Rita Virgínia Salles. Educação infantil: políticas públicas na década de 80. Bauru: EDUS, 2001.

OLIVEIRA, Stela Maris Lagos. A legislação e as políticas nacionais para a educação infantil: avanços, vazios e desvios. In: MACHADO, Maria Lucia A. (Org.). Encontros e desencontros em educação infantil. São Paulo: Cortez, 2002. p. 35-42.

REDIN, Euclides. Atendimento à criança pequena no Brasil. Idéias, São Paulo: FDE, n. 2, p. 27-30, 1988.

ROSEMBERG, Fúlvia. O movimento das mulheres e a abertura política no Brasil: o caso da creche. Cadernos de Pesquisa, São Paulo, n. 51, p. 73-79, nov. 1984.

A educação pré-escolar brasileira durante os governos militares. Cadernos de Pesquisa, São Paulo, n. 82, p. 21-30, ago. 1992.

A LBA, o Projeto Casulo e a Doutrina de Segurança Nacional. FREITAS, Marcos César de. (Org.). História social da infância no Brasil. São Paulo, Cortez, 1997. p. 141161.

Do embate para o debate: educação e assistência no campo da educação infantil. MACHADO, Maria Lucia A. (Org.). Encontros e desencontros em educação infantil. São Paulo: Cortez, 2002. p. 63-78.

Panorama da educação infantil brasileira contemporânea. In: Simpósio Educação Infantil: construindo o presente. Brasília, Anais... Brasília: UNESCO, 2003. p. 33-81.

VIEIRA, Lívia Maria Fraga. A formação do profissional da educação infantil no Brasil no contexto da legislação, das políticas e da realidade do atendimento. Pro-posições, v. 10, n.1 (28), p. 28-39, mar. 1999. 


\section{NOTAS:}

${ }^{1}$ Existem outras e mais abrangentes periodizações para a história da educação infantil brasileira. Kramer (1987), por exemplo, a partir da periodização realizada por Moncorvo Filho (1926), dividiu a história da proteção à infância no Brasil em três períodos: no primeiro, que durou até o ano de 1874, destacam-se as casas dos expostos ou rodas que recebiam crianças pequenas, funcionavam com parcos recursos e em situações precárias de higiene, apresentando altas taxas de mortalidade; o segundo momento compreende o período entre 1874 e 1899, quando médicos, higienistas e industriais se preocuparam com os elevados índices de mortalidade infantil; o terceiro momento, de 1899 a 1930, é marcado pela criação do Instituto de Proteção à Infância, com o objetivo de construir creches e jardins de infância, despertando esferas do governo para os problemas infantis. Kramer (1987), com base no histórico organizado por Moncorvo Filho, estabelece um quarto período na história da educação infantil brasileira, que vai de 1930 a 1980.

${ }^{2} \mathrm{O}$ conteúdo deste artigo faz parte da tese a respeito da relação entre as formas de conceituar os processos de alfabetização e letramento e as funções conferidas à educação infantil brasileira contemporânea, defendida pela autora, em 2009, junto ao Programa de Pós-Graduação em Educação da Universidade de São Paulo.

${ }^{3}$ MICHILES, Carlos. Cidadão constituinte: a saga das emendas populares. Rio de Janeiro, Paz e Terra, 1989.

${ }^{4}$ A teoria da privação cultural não se constitui em um corpo teórico fixo, pois passou, gradativamente, por modificações pautadas em incorporações das diversas críticas que lhe foram feitas, desde o seu aparecimento, no início da década de 1960. Segundo Kramer (1987, p. 33), "a abordagem da privação cultural se apóia no seguinte quadro conceitual: as crianças das classes populares fracassam porque apresentam 'desvantagens socioculturais', ou seja, carências de ordem social. Tais desvantagens são perturbações, ora de ordem intelectual ou lingüística, ora de ordem afetiva: em ambos os casos, as crianças apresentam 'insuficiências' que é necessário compensar através de métodos pedagógicos adequados, se se quer diminuir a diferença entre essas crianças 'desfavoráveis' e as demais, na área do desempenho escolar". Porém, enquanto no Brasil, na década de 1970, a teoria da privação cultural e os programas de educação compensatória ganhavam adeptos e inspiravam os formuladores de políticas voltadas para a educação, nos Estados Unidos e em outros países, vinham sofrendo sérias críticas não apenas por seus efeitos limitados, mas também pelas confusões e contradições inerentes ao conceito de privação cultural (FERRARI; GASPARY, 1980).

${ }^{5}$ BRASIL. II Plano Setorial de Educação e Cultura (1975/1979). Brasília, 1977.

${ }^{6}$ O per capita repassado pela LBA às instituições conveniadas garantia apenas $20 \%$ do custo de manutenção de uma criança. "Em 1986, o per capita para atendimento em 8 horas equivalia a US\$ 4.04, sendo que um estudo realizado pela própria instituição apontava que o custo real de uma criança, neste mesmo regime horário, alçava a US\$26.5, contribuindo em apenas 15\%; em janeiro de 1989 o per capita mensal para atendimento em 8 horas correspondia a US\$ 5.09" (CAMPOS; ROSEMBERG; FEREIRA, 2001, p.32-33).

71979 foi o Ano Internacional da Criança. A temática da infância tornou-se freqüente nos meios de comunicação de massa que divulgaram e denunciaram a situação da criança em idade pré-escolar (KRAMER; SOUZA, 1987, p. 16).

${ }^{8}$ BRASIL. Educação Pré-Escolar: Programa Nacional. Brasília, MEC/SEPS/SER, 1982.

Artigo recebido em: 10/09/2009

Aprovado para publicação em: 30/09/2009 